\title{
Impact of pulmonary hypertension on outcomes after aortic valve replacement for aortic valve stenosis
}

\author{
Spencer J. Melby, MD, Marc R. Moon, MD, Brian R. Lindman, MD, Marci S. Bailey, RN, MSN, \\ Laureen L. Hill, MD, and Ralph J. Damiano, Jr, MD
}

Objective: The presence of pulmonary hypertension historically has been considered a significant risk factor affecting early and late outcomes after valve replacement. Given the number of recent advances in the management of pulmonary hypertension after cardiac surgery, a better understanding of its impact on outcomes may assist in the clinical management of these patients. The purpose of this study was to determine whether pulmonary hypertension remains a risk factor in the modern era for adverse outcomes after aortic valve replacement for aortic valve stenosis.

\begin{abstract}
Methods: From January 1996 to June 2009, a total of 1080 patients underwent aortic valve replacement for primary aortic valve stenosis, of whom $574(53 \%)$ had normal systolic pulmonary artery pressures (sPAP) and $506(47 \%)$ had pulmonary hypertension. Pulmonary hypertension was defined as mild (sPAP 35-44 mm $\mathrm{Hg}$ ), moderate $(45-59 \mathrm{~mm} \mathrm{Hg})$, or severe $(\geq 60 \mathrm{~mm} \mathrm{Hg})$. In the group of patients with pulmonary hypertension, 204 had postoperative echocardiograms.

Results: Operative mortality was significantly higher in patients with pulmonary hypertension $(47 / 506,9 \%$, vs $31 / 574,5 \%, P=.02)$. The incidence of postoperative stroke was similar $(P=.14)$, but patients with pulmonary hypertension had an increased median hospital length of stay ( 8 vs 7 days, $P=.001)$ and an increased incidence of prolonged ventilation $(26 \%$ vs $17 \%, P<.001)$. Preoperative pulmonary hypertension was an independent risk factor for decreased long-term survival (relative risk 1.7, $P=.02$ ). Those with persistent pulmonary hypertension postoperatively had decreased survival. Five-year survival (Kaplan-Meier) was 78\% $\pm 6 \%$ with normal sPAP and $77 \% \pm 7 \%$ with mild pulmonary hypertension postoperatively, compared with $64 \%$ $\pm 8 \%$ with moderate and $45 \% \pm 12 \%$ with severe pulmonary hypertension $(P<.001)$.
\end{abstract}

Conclusions: In patients undergoing aortic valve replacement, preoperative pulmonary hypertension increased operative mortality and decreased long-term survival. Patients with persistent moderate or severe pulmonary hypertension after aortic valve replacement had decreased long-term survival. These data suggest that pulmonary hypertension had a significant impact on outcomes in patients undergoing aortic valve replacement and should be considered in preoperative risk assessment. (J Thorac Cardiovasc Surg 2011;141:1424-30)

Earn CME credits at

http://cme.ctsnetjournals.org

Historically, patients with aortic valve stenosis and pulmonary hypertension $(\mathrm{PH})$ have had impaired left ventricular function, mitral regurgitation, and increased left ventricular end-diastolic pressure (LVEDP). ${ }^{1-3}$ Because of associated morbidities and potential for right heart compromise, $\mathrm{PH}$

\footnotetext{
From the Department of Cardiothoracic Surgery, Washington University School of Medicine, St Louis, Mo.

Disclosures: Authors have nothing to disclose with regard to commercial support.

Read at the 90th Annual Meeting of The American Association for Thoracic Surgery, Toronto, Ontario, Canada, May 1-5, 2010.

Received for publication May 4, 2010; revisions received Feb 3, 2011; accepted for publication Feb 22, 2011.

Address for reprints: Ralph J. Damiano, Jr, MD, Department of Cardiothoracic Surgery, Washington University School of Medicine, Suite 3108, Queeny Tower, St Louis, MO 63110 (E-mail: damianor@wustl.edu).

$0022-5223 / \$ 36.00$

Copyright (C) 2011 by The American Association for Thoracic Surgery doi:10.1016/j.jtcvs.2011.02.028
}

may increase morbidity and mortality when patients with aortic valve stenosis undergo valve replacement. Small observational studies have demonstrated benefit with aortic valve replacement (AVR) in patients with aortic stenosis and $\mathrm{PH}$ in both symptoms and 5-year survivals when compared with medically managed patients. ${ }^{2-6}$ AVR in these patients may decrease strain on the right heart with left ventricular unloading, thus improving survival. However, there have been no large studies to date characterizing the outcomes of patients with $\mathrm{PH}$ despite the possible increased risks.

Surgery in the setting of PH may carry a higher risk than in patients without $\mathrm{PH}$ owing to fixed vasculopathy and right heart failure. These comorbid conditions can make postoperative care challenging. There has not yet been sufficient evidence in the literature to define an increase in risk for patients who undergo AVR for aortic stenosis with PH. Transcatheter approaches are currently being used to treat high-risk patients and determination of additional risk posed by $\mathrm{PH}$ may aid in selection of patients for intervention by surgery, transcatheter approach, or medical treatment alone. 

Abbreviations and Acronyms
AVR = aortic valve replacement
$\mathrm{CABG}=$ coronary artery bypass graft
LVEDP $=$ left ventricular end-diastolic pressure
LVEF = left ventricular ejection fraction
PAP = pulmonary artery pressure
$\mathrm{PH} \quad=$ pulmonary hypertension
PVR = pulmonary vascular resistance
$\mathrm{RR} \quad=$ relative risk
sPAP $=$ systemic pulmonary arterial pressure

We reviewed our database of patients who underwent AVR for aortic stenosis from 1996 through 2009 to evaluate longterm survival and to determine whether $\mathrm{PH}$ is a risk factor in patients undergoing AVR for aortic stenosis.

\section{PATIENTS AND METHODS}

This retrospective study was approved by the Institutional Review Board of Washington University School of Medicine, and individual consent was waived. Between January 1, 1996, and June 30, 2009, a total of 1777 patients underwent AVR with or without concomitant procedures (coronary artery bypass graft; mitral, tricuspid, or pulmonary valve repair or replacement; atrial septal defect repair; ventricular septal defect repair; or arrhythmia surgery). A total of 697 patients had a Ross procedure, endocarditis, aneurysm reconstruction, or aortic regurgitation as the primary diagnosis and these were excluded from analysis, leaving 1080 patients for review. AVR was performed in accordance with American College of Cardiology/American Heart Association guidelines and indications for valve replacement in patients with aortic stenosis. ${ }^{7,8}$ Preoperative demographic information and perioperative events were stored in a computerized database. Fourteen surgeons of the Division of Cardiothoracic Surgery, Washington University in St Louis, performed the procedures at BarnesJewish Hospital. Although approaches varied among surgeons, all procedures were done with cardiopulmonary bypass with mild systemic hypothermia $\left(30^{\circ} \mathrm{C}-34^{\circ} \mathrm{C}\right)$. Myocardial protection was achieved with cold blood cardioplegia. The procedures were performed with either a standard or partial median sternotomy. The selection of valve prosthesis type was at the discretion of the operating surgeon. There has been a strong institutional preference for biological valves in patients older than 65 years and in younger patients who want to avoid coumadin. Coronary artery bypass grafts (CABG) were performed for recognized indications in 428 patients.

Patients were evaluated prospectively for the presence $\mathrm{PH}$ (systemic pulmonary artery pressure $[\mathrm{sPAP}] \geq 35 \mathrm{~mm} \mathrm{Hg}$ ) or absence of $\mathrm{PH}$ (sPAP of $<35 \mathrm{~mm} \mathrm{Hg}$ ) by either echocardiography or right heart catheterization. These were recorded and entered prospectively into the database. Fortyseven percent (506/1080) of patients had PH. Patients with PH were further subdivided into groups of mild (sPAP 35-44 mm Hg), moderate (sPAP 45$59 \mathrm{~mm} \mathrm{Hg}$ ), or severe ( $\mathrm{sPAP} \geq 60 \mathrm{~mm} \mathrm{Hg}$ ). Mean duration of follow-up was $4.5 \pm 3.5$ years for patients without $\mathrm{PH}$ and $3.4 \pm 3.2$ years for patients with PH. Overall mean follow-up was $4.0 \pm 3.4$ years. Echocardiographic follow-up consisted of those patients who survived surgery and had postoperative echocardiograms $(284 / 1008,28 \%)$ at an average of $3.1 \pm 2.7$ years after surgery, which were reviewed for assessment of sPAP.

Operative mortality was defined as death within 30 days or before discharge from the hospital. Preoperative, operative, and postoperative variables including operative mortality were compared between the early and late eras in the study: the early group underwent surgery from January of 1996 through December 31, 2002 (7 years, 172 patients) and the late group of patients had surgery from January 1, 2003, through June 30, 2009 (6.5 years, 334 patients). Continuous data are expressed as mean \pm standard deviation and categorical data are expressed as counts and proportions. The Kaplan-Meier estimate was used to depict survival over time among operative survivors. The $\chi^{2}$ or Fisher exact univariate tests were used to analyze differences in proportions in the categorical data. Factors found to trend toward significance (gender, age, PH, isolated AVR, New York Heart Association class III or IV, myocardial infarction, stroke, left ventricular ejection fraction (LVEF), systemic hypertension, diabetes, renal failure, dialysis, atrial fibrillation, hypercholesterolemia, chronic obstructive pulmonary disease, previous CABG, body surface area, and intraaortic balloon pump at the time of surgery) by univariate testing $(P \leq .10)$ were entered into a multivariate analysis. The Cox multivariate proportional hazards regression model was used to identify independent prognostic factors for death. Relative risks (RR) with $95 \%$ confidence intervals were calculated for each of the significant risk factors. All data analysis was performed using SPSS 11.0 (SPSS Inc, Chicago, Ill) for Windows (Microsoft Corp, Redmond, Wash).

\section{RESULTS}

Compared with patients with normal SPAP, patients with $\mathrm{PH}$ were significantly older (72 vs 70 years old, $P=.004$ ), more often in New York Heart Association class III or IV ( $77 \%$ vs $59 \%, P<.001)$, and had a prior myocardial infarction $(29 \%$ vs $19 \%, P<.001)$, diabetes $(37 \%$ vs $23 \%$, $P<.001)$, hypertension ( $74 \%$ vs $69 \%, P=.01)$, and lower LVEF $(46 \%$ vs $52 \%, P<.001)$ (Table 1 ). More concomitant procedures were done on patients with $\mathrm{PH}(51.9 \%$ vs $43.5 \%$ ), and subsequently the cardiopulmonary bypass time was slightly longer in these patients (160 minutes vs 153 minutes, $P=.034)$. Patients with $\mathrm{PH}$ had longer ventilation times (26.1 hours vs 16.7 hours, $P<.001$ ). Although they had a higher rate of cerebrovascular accident, this was not statistically different $(4.5 \%$ vs $2.8 \%, P=.14)$.

Operative mortality was statistically higher in patients with $\mathrm{PH}(9.3 \%$ vs $5.4 \%, P=.018)$. Cox regression multivariate analysis demonstrated that mortality was adversely affected by the presence of renal failure $(\mathrm{RR}=2.5$, $P<.001)$, diabetes $(\mathrm{RR}=1.7, P<.001)$, previous cardiac surgery $(\mathrm{RR}=1.6, P=.001)$, and $\mathrm{PH}(\mathrm{RR}=1.5, P=.002)$, as well as age $(\mathrm{RR}=1.04, P<.001)$ and $\mathrm{LVEF}(\mathrm{RR}=0.99$, $P=.05$ ) (Table 2).

Evaluation of early versus late era of surgery showed that preoperative and intraoperative variables were similar except for LVEF $(40 \% \pm 16 \%$ vs $48 \% \pm 16 \%, P<.001)$, percentage of patients who underwent isolated AVR $(36 \%$ [62 patients] vs $47 \%$ [ 158 patients], $P=.02$ ), cardiopulmonary bypass time $(181 \pm 56$ minutes vs $149 \pm 57$ minutes, $P<.001)$, and crossclamp time $(131 \pm 47$ minutes vs $98 \pm$ 47 minutes, $P<.001)$ in the early versus late groups, respectively. Patients who had surgery in the first 7 years of the study had an operative mortality of $8.7 \%$ (15/172) whereas for those who underwent surgery in the late era it was $9.6 \%$ $(32 / 334, P=.8)$.

Survival was further evaluated on the basis of severity of PH including 4 subgroups: no PH (sPAP $<35 \mathrm{~mm} \mathrm{Hg}$, 
TABLE 1. Baseline clinical characteristics

\begin{tabular}{|c|c|c|c|}
\hline Variable & $\begin{array}{l}\text { AVR with PH } \\
\quad(\mathbf{n}=506)\end{array}$ & $\begin{array}{c}\text { AVR no PH } \\
(\mathrm{n}=574) \\
\end{array}$ & $\begin{array}{c}P \\
\text { value } \\
\end{array}$ \\
\hline Preoperative variables & $(\%)$ & $(\%)$ & \\
\hline Age (y) & $72.3 \pm 10.7$ & $70.2 \pm 13.5$ & .004 \\
\hline Male gender & $299(59.1)$ & $332(57.8)$ & .711 \\
\hline NYHA III or IV & $390(77.1)$ & $338(58.9)$ & $<.001$ \\
\hline COPD & $44(8.7)$ & $44(7.7)$ & .578 \\
\hline MI & $147(29.1)$ & $111(19.3)$ & $<.001$ \\
\hline Diabetes & $188(37.2)$ & $129(22.5)$ & $<.001$ \\
\hline Hypertension & 374 (73.9) & $384(66.9)$ & .014 \\
\hline LVEF & $46 \pm 15$ & $52 \pm 13$ & $<.001$ \\
\hline Previous CPB surgery & $107(21)$ & $88(15)$ & .014 \\
\hline \multicolumn{4}{|l|}{ Operative variables } \\
\hline Isolated AVR & $220(43.5)$ & $298(51.9)$ & .003 \\
\hline \multicolumn{4}{|l|}{ Concomitant procedures } \\
\hline $\mathrm{CABG} \pm$ other & 193 & 209 & \\
\hline CABG + MVR & 21 & 5 & \\
\hline $\mathrm{MV} \pm$ other & 38 & 9 & \\
\hline Other & 34 & 52 & \\
\hline CPB time & $160 \pm 57$ & $153 \pm 54$ & .034 \\
\hline Aortic crossclamp time & $109 \pm 45$ & $106 \pm 40$ & .297 \\
\hline \multicolumn{4}{|l|}{ Postoperative variables } \\
\hline Prolonged ventilation & $132(26.1)$ & $96(16.7)$ & $<.001$ \\
\hline CVA & $23(4.5)$ & $16(2.8)$ & .142 \\
\hline Atrial fibrillation/flutter & $180(36)$ & $201(35)$ & .849 \\
\hline Placement of IABP & $56(11)$ & $15(3)$ & $<.001$ \\
\hline Operative mortality & $47(9.3)$ & $31(5.4)$ & .018 \\
\hline Median LOS (d) & $8(6-84)$ & $7(6-91)$ & .001 \\
\hline Total follow-up (y) & $3.4 \pm 3.2$ & $4.4 \pm 3.5$ & $<.001$ \\
\hline
\end{tabular}

Continuous data are presented as mean \pm standard deviation. AVR, Aortic valve replacement; $P H$, pulmonary hypertension; $N Y H A$, New York Heart Association Functional Heart Failure class; $C O P D$, chronic obstructive pulmonary disease; $M I$, myocardial infarction; $L V E F$, left ventricular ejection fraction; $C P B$, cardiopulmonary bypass; $C A B G$, coronary artery bypass graft; $M V R$, mitral valve repair or replacement; $M V$, mitral valve; $C V A$, cerebrovascular accident; IABP, intra-aortic balloon pump; LOS, length of stay. Other operations include tricuspid valve, pulmonary valve, atrial septal defect, ventricular septal defect, and surgery for arrhythmia.

$\mathrm{n}=66$ ), mild PH (sPAP 35-44 mm Hg, $\mathrm{n}=125$ ), moderate PH (sPAP 45-59 mm Hg, $\mathrm{n}=129$ ), and severe PH (sPAP $\geq$ $60 \mathrm{~mm} \mathrm{Hg}, \mathrm{n}=102$ ). Kaplan-Meier analysis of patients with preoperative $\mathrm{PH}$ showed that survival was significantly worse in the more severe PH groups $(P=.020)$ (Figure 1). Similarly, analysis was completed using measurements of patients' postoperative SPAP, demonstrating that 5-year survival was diminished in those with more severe $\mathrm{PH}$ versus those with mild or no $\mathrm{PH}(45 \%$ vs $78 \%, P<.001)$ (Figure 2 ).

Evaluation of patients with high pulmonary vascular resistance (PVR) was done by calculating the PVR using pulmonary artery pressure (PAP), LVEDP, and cardiac output (CO): (mean PAP - LVEDP)/(CO) and then evaluating survival comparing patients with PVR of less than 3 Wood units versus those with 3 Wood units or more. Kaplan-Meier analysis showed that survival was decreased in those with higher PVR (5-year survival $49 \%$ vs $72 \%$, $P=.001$ ) (Figure 3).
TABLE 2. Multivariate Cox regression analysis of risk factors for decreased survival after AVR for aortic stenosis $(n=1080)$

\begin{tabular}{lrllr}
\hline \multicolumn{1}{c}{ Variable } & \multicolumn{1}{c}{ N } & \multicolumn{1}{c}{ RR } & \multicolumn{1}{c}{$\mathbf{9 5} \%$ CI } & $\boldsymbol{P}$ value \\
\hline Pulmonary hypertension & 506 & 1.51 & $1.160-1.965$ & $\mathbf{. 0 0 2}$ \\
Age (y) & 1080 & 1.036 & $1.020-1.051$ & $<.001$ \\
Diabetes & 317 & 1.697 & $1.120-3.875$ & $<.001$ \\
Renal failure & 93 & 2.505 & $1.613-3.890$ & $<.001$ \\
Dialysis & 40 & 2.083 & $1.308-2.202$ & $\mathbf{. 0 2 0}$ \\
NYHA class III or IV & 728 & 1.507 & $1.101-2.061$ & $\mathbf{. 0 1 0}$ \\
LVEF (\%) & 876 & 0.991 & $0.983-1.000$ & $\mathbf{. 0 4 9}$ \\
Previous cardiopulmonary bypass & 195 & 1.631 & $1.210-2.198$ & $\mathbf{. 0 0 1}$ \\
\hline F
\end{tabular}

Factors found to trend toward significance (gender, age, pulmonary hypertension, isolated aortic valve replacement [AVR], New York Heart Association [NYHA] class III or IV, myocardial infarction, stroke, left ventricular ejection fraction [LVEF], systemic hypertension, diabetes, renal failure, dialysis, atrial fibrillation, hypercholesterolemia, chronic obstructive pulmonary disease, previous cardiac surgery requiring cardiopulmonary bypass, body surface area) by univariate testing $(P \leq .10)$ were analyzed. Gender, isolated aortic valve replacement, myocardial infarction, stroke, systemic hypertension, atrial fibrillation, hypercholesterolemia, chronic obstructive pulmonary disease, and body surface area were not found to be significant independent predictors for lower survival after aortic valve replacement for aortic stenosis in the mitral valve model. $R R$, Relative risk; $C I$, confidence intervals.

Patients with mild PH showed no improvement in sPAP when comparing postoperative measurements with preoperative $(P=.22)$ (Table 3$)$. In contrast, sPAP fell after AVR in patients with moderate $\mathrm{PH}(51 \pm 4 \mathrm{~mm} \mathrm{Hg}$ vs $45 \pm 16 \mathrm{~mm}$ $\mathrm{Hg}, P=.01)$, with an even more substantial fall in patients with severe $\mathrm{PH}(69 \pm 12 \mathrm{~mm} \mathrm{Hg}$ vs $45 \pm 14 \mathrm{~mm} \mathrm{Hg}$, $P<.001$ ) (Table 3).

To eliminate potential conflicting impact of associated mitral valve and other valvular diseases, we repeated the analysis, looking specifically at patients who underwent only AVR or AVR + CABG, excluding all the patients who had concomitant valve surgery. In this group of patients $(\mathrm{n}=978$ patients) we found similar changes: operative mortality was $5.2 \%(28 / 542)$ in those with no $\mathrm{PH}$, whereas for those with $\mathrm{PH}$ it was $8.0 \%(35 / 436, P=.08)$. The fall in

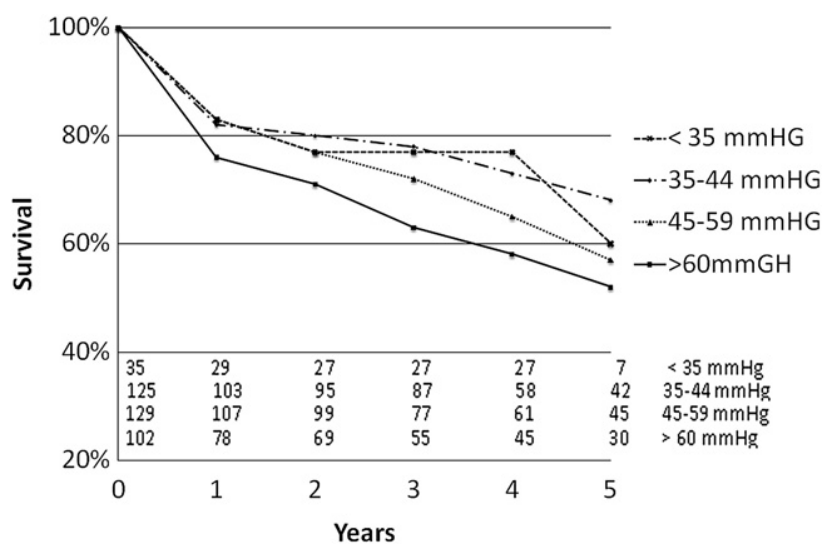

FIGURE 1. Kaplan-Meier survival curve based on preoperative pulmonary artery pressure. Number at each time point is depicted at the bottom of the graph. 


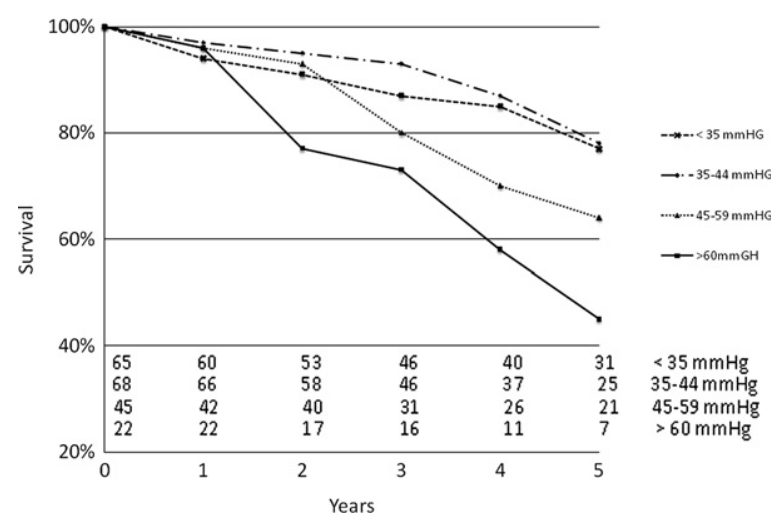

FIGURE 2. Kaplan-Meier survival curve based on postoperative pulmonary artery pressure. Number at each time point is depicted at the bottom of the graph.

SPAP for those with PH was similar to that for the overall group as well (preoperative sPAP $50.1 \mathrm{~mm} \mathrm{Hg} \pm 13.5$ $\mathrm{mm} \mathrm{Hg}$ fell postoperatively to $41.1 \mathrm{~mm} \mathrm{Hg} \pm 13.5 \mathrm{~mm} \mathrm{Hg}$ ).

\section{DISCUSSION}

$\mathrm{PH}$ is common among patients who undergo AVR for stenosis. ${ }^{4,6,9}$ In this study, PH was present in $47 \%$ of patients who underwent AVR. Despite this, there have been no large scale studies that have delineated the risks of this comorbidity or what the outcomes are after AVR. Furthermore, the presence of any $\mathrm{PH}$ is not considered in major preoperative risk assessment tools available. The EuroSCORE uses only the presence of severe PH (PAP > $60 \mathrm{~mm} \mathrm{Hg}$ ) and the Society of Thoracic Surgeons risk calculator does not consider $\mathrm{PH}$ at all. ${ }^{10-12}$

Several small observational studies have shown improvement in outcome for patients who underwent AVR with PH compared with medically treated patients. Malouf and associates $^{3}$ compared 37 patients with severe $\mathrm{PH}$ who underwent AVR with a group of 10 similar patients who were treated medically. In that study there was improved survival at 5 years $(52 \%$ vs $20 \%)$. In another retrospective study by Pai and colleagues, ${ }^{5} 36$ patients with severe aortic stenosis and PH underwent surgery and were compared with 83 who were treated medically. After adjustment for comorbidities, the authors found an improvement in 5-year survival (65\% vs $20 \%$ ) compared with the nonoperative group. These studies demonstrated better outcomes in patients undergoing AVR versus medical therapy alone; however, the number of patients in these studies was small and comparison between groups was difficult because many of the medically treated patients were likely deemed inoperable owing to comorbidities. In a study of 92 patients by Johnson and coauthors, ${ }^{2} 13$ of 15 patients with severe $\mathrm{PH}$ underwent AVR for stenosis and there was no operative mortality. In a study by Tracy, Proctor, and Hizny, ${ }^{4} 37$ of $52(70 \%)$ patients undergoing AVR for aortic stenosis had PH, with

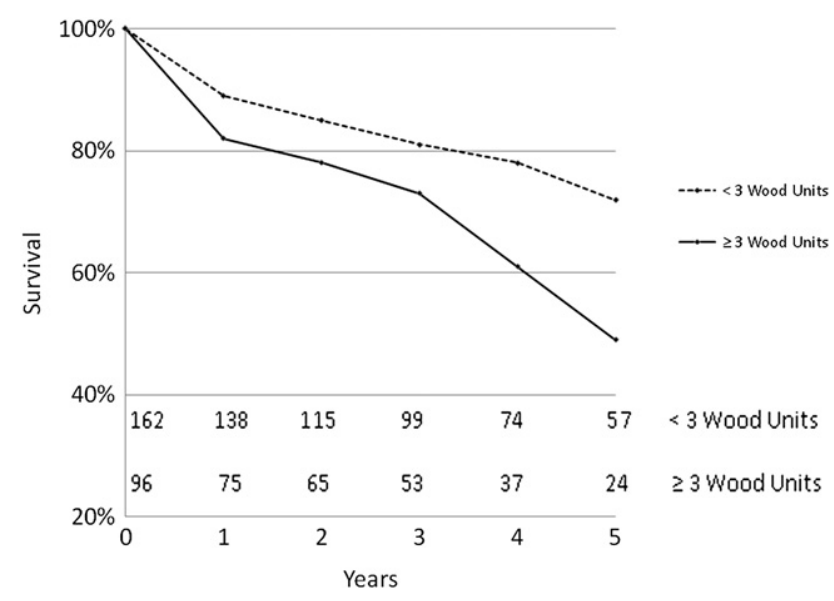

FIGURE 3. Kaplan-Meier survival curve based on preoperative pulmonary artery vascular resistance. Number at each time point is depicted at the bottom of the graph.

an operative mortality of only $1.9 \%$. From these small studies it was difficult to draw adequate conclusions about operative mortality in patients with PH. In the current report, operative mortality was nearly twice as high when $\mathrm{PH}$ was present $(9.3 \%$ vs $5.4 \%)$, similar to previous reports. ${ }^{10}$ Because survival is influenced by the presence of $\mathrm{PH}$, and because more than 200,000 AVRs are done annually worldwide, determination of its incremental risk is warranted. ${ }^{11}$

Historical studies have shown that patients with $\mathrm{PH}$ have worse outcomes after AVR for aortic stenosis. Copeland and others ${ }^{9}$ showed in an early report of 1127 patients undergoing isolated AVR that the presence of mean PAP of $30 \mathrm{~mm} \mathrm{Hg}$ or more $(\mathrm{n}=173)$ decreased long-term survival compared with those with a mean PAP less than 30 ( $\mathrm{n}=492, P=.006)$. We similarly found that in the presence of preoperative $\mathrm{PH}$, long-term survival is compromised. In this study, the degree of $\mathrm{PH}$ affected adversely the longterm survival, inasmuch as those with moderate and severe PH had only $57 \%$ and $52 \% 5$-year survivals whereas those with no or mild PH had $68 \%$ and $62 \%$ 5-year survivals. In addition, those with persistent postoperative moderate or severe $\mathrm{PH}$ also had even worse 5-year survival (45\%-64\%) than did those without or with mild postoperative $\mathrm{PH}$ $(77 \%-78 \%$, Figure 1$)$.

TABLE 3. Change in systolic pulmonary artery pressure after aortic valve replacement in patients with mild, moderate, and severe pulmonary hypertension

\begin{tabular}{lccr}
\hline \multicolumn{1}{c}{ Group } & $\begin{array}{c}\text { Mean } \\
\text { preop sPAP }\end{array}$ & $\begin{array}{c}\text { Mean } \\
\text { postop sPAP }\end{array}$ & $\begin{array}{c}\boldsymbol{P} \\
\text { value }\end{array}$ \\
\hline $35-44 \mathrm{~mm} \mathrm{Hg}(\mathrm{n}=61)$ & $39 \pm 3$ & $37 \pm 11$ & .218 \\
$45-59 \mathrm{~mm} \mathrm{Hg}(\mathrm{n}=58)$ & $51 \pm 4$ & $45 \pm 16$ & .014 \\
$\geq 60 \mathrm{~mm} \mathrm{Hg}(\mathrm{n}=46)$ & $69 \pm 12$ & $45 \pm 14$ & $<.001$ \\
Overall group & $51 \pm 14$ & $42 \pm 14$ & $<.001$ \\
\hline
\end{tabular}

preop, Preoperative; postop, postoperative; $s P A P$, systolic pulmonary artery pressure. 
Advances in the treatment of $\mathrm{PH}$, such as prostacyclin, intravenous milrinone, inhaled nitric oxide, sildenafil, and other modalities, have ameliorated some of the physiologic consequences of $\mathrm{PH}^{12-14}$ Almost half of patients undergoing surgery for aortic stenosis have PH (in both this and other studies), ${ }^{4,6,9}$ and therefore continued efforts to improve the treatment of these patients is warranted. Our current first-line treatment strategy for patients with $\mathrm{PH}$ is typically inhaled epoprostenol with concurrent inotropic support as the intraoperative or postoperative hemodynamics warrant (ie, elevated PAPs and evidence of or concern for right heart failure). Inhaled nitric oxide is not used as a first-line agent despite its efficacy owing to cost considerations. Inhaled pulmonary vasodilator therapy is usually continued for the first 24 hours and then weaned as right heart function tolerates. Inotropic therapy is usually maintained until pulmonary vasodilator therapy is weaned substantially or discontinued. Rarely, long-term oral medications are administered (ie, sildenafil or bosentan) and usually only in patients previously taking these drugs. These treatment strategies are used for management of $\mathrm{PH}$ in general and are not unique to patients undergoing AVR inasmuch as little scientific evidence is available on improvement in outcomes after AVR.

A transcatheter approach for the treatment of aortic stenosis is being performed for high-risk patients at several centers throughout the world. The mortality rate for this procedure was higher in the presence of $\mathrm{PH}$ in 1 study: in 345 procedures on 339 patients, the relative risk of mortality within 30 days was 2.1 for patients with $\mathrm{PH} .{ }^{15} \mathrm{PH}$ has also been found to be a risk factor in octogenarians undergoing cardiac operations. ${ }^{16}$ Preoperative risk assessment is an important part of the decision-making process of whether patients should undergo a surgical or transcatheter valve implantation procedure for aortic stenosis. Although it has been shown that high-risk patients can successfully undergo surgery, including the elderly and patients with other comorbidities, ${ }^{17-19}$ an accurate risk assessment is critical to an informed discussion between the surgeon and patient so that appropriate decisions can be made as to whether an intervention should be performed and which approach should be undertaken. The current study demonstrated that operative mortality nearly doubled in the presence of $\mathrm{PH}$, and 5-year survival was significantly diminished in those with severe preoperative $\mathrm{PH}$ versus those with mild or no $\mathrm{PH}(52 \%$ vs $60 \%-68 \%$, respectively).

Multiple factors can contribute to and influence PAPs, including PVR, right heart function, and left ventricular systolic and diastolic function. It remains unclear whether some underlying causes or consequences of $\mathrm{PH}$ may contribute more to the adverse outcomes observed. For example, elevated LVEDP has also been shown to be an independent risk factor in coronary cardiac surgery. ${ }^{20}$ This study demonstrated that survival was decreased in the presence of
PVR. PVR is another measurement that is often used to describe the severity of the pulmonary vascular disease in patients with $\mathrm{PH}$. The equation that describes it is as follows: PVR $=($ mean PAP - PAWP $[$ LVEDP $] / C O) \times 80$ (this gives PVR in dyn-s $/ \mathrm{cm}^{5}$ ), where PAWP is pulmonary artery wedge pressure and $\mathrm{CO}$ is cardiac output. For Wood units, the following is used: mean PAP - (PAWP/CO). Those with a PVR of more than 3 Wood units had $49 \%$ 5 -year survival versus those with normal PVR, who had $72 \%$ 5-year survival. The presence of increased PVR clearly portends a worse outcome. The different causes of $\mathrm{PH}$ (eg, whether it is due to cardiac disease or whether it is from pulmonary disease) may influence outcomes differently. However, elevated PVR is sometimes due to intrinsic lung vascular disease, but can also be an effect of long-term elevated LVEDPs. This current study evaluated a heterogeneous group of patients with $\mathrm{PH}$ from multiple causes, likely including some individuals with $\mathrm{PH}$ owing to elevated LVEDP as well as other patients who had PH owing to lung disease or to intrinsic pulmonary vascular disease. Further studies need to be done to elucidate which preoperative variables associated with $\mathrm{PH}$, including etiology, affect survival. The presence of elevated PVR likely plays a critical role.

\section{Limitations}

Retrospective studies have inherent limitations. Followup was not complete in all 1080 patients. However, there were sufficient numbers included in the study to determine outcomes in groups both with and without PH. Several surgeons were involved during this 13-year period, which could increase the variability of the data. The large number of surgeons would, however, limit the effect that surgeondependent factors might have had on outcomes. Echocardiographic studies used estimations of PAP whereas the catheterization methods used direct measurements; the estimation method may have decreased the overall accuracy of the PAP measurements. Furthermore, echocardiography and catheterization data were not collected on every patient owing to the large number of patients over the extended study period. This could introduce selection bias for sicker patients who may undergo more extensive studies such as echocardiography or catheterization allowing identification of PH more often in this group of patients with more comorbidities.

Inclusion of patients with mitral valve disease severe enough to warrant surgical intervention may be considered a confounding factor. However, analysis of mortality and major morbidity after excluding this group of patients yielded results very similar to the analysis of those who had mitral valve disease. As the etiologies of PH are likely multifactorial in many cases, inclusion of these patients better represents the real-world scenario of those who need surgery for severe aortic stenosis. Further studies are needed to 
elucidate which causative factors of PH have the highest impact on outcome.

\section{SUMMARY}

In patients undergoing AVR for aortic stenosis, PH increased operative and long-term mortality. Earlier intervention-before irreversible changes in the pulmonary circulation can occur-should be considered for asymptomatic or minimally symptomatic patients with significant aortic stenosis and moderate to severe PH. It is important for surgeons to consider $\mathrm{PH}$ in preoperative risk assessment of patients undergoing AVR.

\section{References}

1. Faggiano P, Antonini-Canterin F, Ribichini F, D'Aloia A, Ferrero V, Cervesato E, et al. Pulmonary artery hypertension in adult patients with symptomatic valvular aortic stenosis. Am J Cardiol. 2000;85:204-8.

2. Johnson LW, Hapanowicz MB, Buonanno C, Bowser MA, Marvasti MA, Parker FB Jr. Pulmonary hypertension in isolated aortic stenosis: hemodynamic correlations and follow-up. J Thorac Cardiovasc Surg. 1988;95:603-7.

3. Malouf JF, Enriquez-Sarano M, Pellikka PA, Oh JK, Bailey KR, Chandrasekaran K, et al. Severe pulmonary hypertension in patients with severe aortic valve stenosis: clinical profile and prognostic implications. J Am Coll Cardiol. 2002;40:789-95.

4. Tracy GP, Proctor MS, Hizny CS. Reversibility of pulmonary artery hypertension in aortic stenosis after aortic valve replacement. Ann Thorac Surg. 1990;50: 89-93.

5. Pai RG, Varadarajan P, Kapoor N, Bansal RC. Aortic valve replacement improves survival in severe aortic stenosis associated with severe pulmonary hypertension. Ann Thorac Surg. 2007;84:80-5.

6. Snopek G, Pogorzelska H, Zielinski T, Rajecka A, Korewicki J, Biederman A, et al. Valve replacement for aortic stenosis with severe congestive heart failure and pulmonary hypertension. J Heart Valve Dis. 1996;5:268-72.

7. Bonow RO, Carabello BA, Kanu C, de Leon AC Jr, Faxon DP, Freed MD, et al. ACC/AHA 2006 guidelines for the management of patients with valvular heart disease: a report of the American College of Cardiology/American Heart Association Task Force on Practice Guidelines (writing committee to revise the 1998 Guidelines for the Management of Patients With Valvular Heart Disease): developed in collaboration with the Society of Cardiovascular Anesthesiologists: endorsed by the Society for Cardiovascular Angiography and Interventions and the Society of Thoracic Surgeons. Circulation. 2006;114:e84-231.

8. Bonow RO, Carabello B, de Leon AC Jr, Edmunds LH Jr, Fedderly BJ, Freed MD, et al. Guidelines for the management of patients with valvular heart disease: executive summary. A report of the American College of Cardiology/ American Heart Association Task Force on Practice Guidelines (Committee on Management of Patients with Valvular Heart Disease). Circulation. 1998;98: 1949-84.

9. Copeland JG, Griepp RB, Stinson EB, Shumway NE. Long-term follow-up after isolated aortic valve replacement. J Thorac Cardiovasc Surg. 1977;74:875-89.

10. Copeland JG, Griepp RB, Stinson EB, Shumway NE. Isolated aortic valve replacement in patients older than 65 years. JAMA. 1977;237:1578-81.

11. Brown JM, O'Brien SM, Wu C, Sikora JA, Griffith BP, Gammie JS. Isolated aortic valve replacement in North America comprising 108,687 patients in 10 years: changes in risks, valve types, and outcomes in the Society of Thoracic Surgeons National Database. J Thorac Cardiovasc Surg. 2009;137:82-90.

12. De Wet CJ, Affleck DG, Jacobsohn E, Avidan MS, Tymkew H, Hill LL, et al. Inhaled prostacyclin is safe, effective, and affordable in patients with pulmonary hypertension, right heart dysfunction, and refractory hypoxemia after cardiothoracic surgery. J Thorac Cardiovasc Surg. 2004;127:1058-67.

13. Klodell CT Jr, Morey TE, Lobato EB, Aranda JM Jr, Staples ED, Schofield RS, et al. Effect of sildenafil on pulmonary artery pressure, systemic pressure, and nitric oxide utilization in patients with left ventricular assist devices. Ann Thorac Surg. 2007;83:68-71; discussion 71.

14. Trachte AL, Lobato EB, Urdaneta F, Hess PJ, Klodell CT, Martin TD, et al. Oral sildenafil reduces pulmonary hypertension after cardiac surgery. Ann Thorac Surg. 2005;79:194-7; discussion 197.
15. Rodes-Cabau J, Webb JG, Cheung A, Ye J, Dumont E, Feindel CM, et al. Transcatheter aortic valve implantation for the treatment of severe symptomatic aortic stenosis in patients at very high or prohibitive surgical risk: acute and late outcomes of the multicenter Canadian experience. J Am Coll Cardiol. 2010;55: 1080-90.

16. Kirsch M, Guesnier L, LeBesnerais P, Hillion ML, Debauchez M, Seguin J, et al. Cardiac operations in octogenarians: perioperative risk factors for death and impaired autonomy. Ann Thorac Surg. 1998;66:60-7.

17. Melby SJ, Zierer A, Kaiser SP, Guthrie TJ, Keune JD, Schuessler RB, et al. Aortic valve replacement in octogenarians: risk factors for early and late mortality. Ann Thorac Surg. 2007;83:1651-6; discussion 1656-7.

18. Florath I, Rosendahl UP, Mortasawi A, Bauer SF, Dalladaku F, Ennker IC, et al. Current determinants of operative mortality in 1400 patients requiring aortic valve replacement. Ann Thorac Surg. 2003;76:75-83.

19. Vaquette B, Corbineau H, Laurent M, Lelong B, Langanay T, de Place C, et al Valve replacement in patients with critical aortic stenosis and depressed left ventricular function: predictors of operative risk, left ventricular function recovery, and long term outcome. Heart. 2005;91:1324-9.

20. Sastry P, Theologou T, Field M, Shaw M, Pullan DM, Fabri BM. Predictive accuracy of EuroSCORE: is end-diastolic dysfunction a missing variable? Eur J Cardiothorac Surg. 2010;37:261-6.

\section{Discussion}

Dr James S. Gammie (Baltimore, Md). Dr Melby and colleagues from Washington University are to be congratulated on a well-presented study. Previous work has clearly demonstrated that unoperated aortic stenosis with $\mathrm{PH}$ is associated with a particularly dismal prognosis. It is also clear from the literature that development of $\mathrm{PH}$ in patients with aortic stenosis is associated with the presence of symptoms, a decline in left ventricular systolic ejection performance, and, most importantly and closely, with diastolic dysfunction as measured by elevated LVEDP and echocardiographic indices of impaired left ventricular relaxation.

PH has not been included in risk models assessing the outcomes after AVR, and thus this work contributes to the literature. The current Society of Thoracic Surgeons risk models do not include PAP because this variable is infrequently collected, and, in fact, in recent years has only been collected in $30 \%$ of patients. There is clear room for improvement here.

I would like to emphasize a key finding of your study, which was more clear in the manuscript than in the presentation: your multivariable models demonstrated that the presence of $\mathrm{PH}$ was not a risk factor for perioperative mortality, and thus we can conclude that $\mathrm{PH}$ in patients with aortic stenosis compromises long-term survival but not short-term surgical outcomes.

Your study was heterogeneous in that it included both isolated AVRs as well as AVRs performed with CABG. Did you look at your isolated aortic valve population and did you find that $\mathrm{PH}$ had a similar impact on outcomes?

Dr Melby. Thank you, Dr Gammie. With respect to the perioperative mortality, our perioperative mortality did almost double, but the review with multivariate analysis did not show that it was an independent risk factor. We did not have the chance to go back-and it is certainly something we will look at in the future-to look at just the patients who had only AVR. As you saw, that was about half of our patients. We have encountered the problem that you mentioned, which is that it is not a frequently reported number. As you start to cut your group down, you start to lose patients and you have weaker results. We looked at the entire group and not exclusively at those who had only AVR, but certainly that would be worth looking at in the future. 
Dr Gammie. Did you look separately at your subset of patients that had more significant $\mathrm{PH}$, those that you classified as moderate or severe?

Dr Melby. When we did our Kaplan-Meier analysis, we created categories of mild, moderate, and severe $\mathrm{PH}$ and found that those with more significant $\mathrm{PH}$ indeed had a significantly worse longterm survival. When we looked at the perioperative mortality, once again, it was not a significant independent risk factor, although it was a significant univariate risk factor. Likely, the increased risk of perioperative death is associated with the multiple comorbidities.

Dr Gammie. This series spanned 13 years, during which time greater use of nitric oxide and intravenous phosphodiesterase inhibitors occurred. In addition to these modalities, there are now 3 classes of oral medications available to treat $\mathrm{PH}$, including prostacyclins, endothelin receptor antagonists, and oral phosphodiesterase inhibitors. Given your findings and the impressive fact that half of these patients are dead 5 years after surgery, do you think that we should consider treating these patients after heart valve surgery much as we treat post-CABG patients, with statins? Also, do you think these results would have an impact on indications for AVR?

Dr Melby. Thank you. Indeed, we have been treating PH more aggressively and using some of the medications that you mentioned, nitric oxide and epoprostenol, or Flolan, commonly in the postoperative period. Unfortunately, there is very little literature on this and no one has looked specifically at the question you asked. We have looked at our data and recognize that these are important questions, specifically who needs to be treated. We are trending toward looking preoperatively more on patients with $\mathrm{PH}$ if they react to some of these medications because it seems to be a trend that if you get a nitric challenge and your PAP does not fall, you do more poorly with surgery. However, these are difficult questions that are going to require more studies. We have not done such studies yet, but we need to do so.

Dr Randall B. Griepp (New York, NY). You define PH in terms of PAP rather than the resistance across the pulmonary vascular bed, and consequently it has both the component of PVR per se as well as left ventricular filling pressure. I wonder whether a good part of this effect may just be that you are measuring a surrogate for left ventricular failure, either the dilated systolically failing ventricle or the very hypertrophied diastolically dysfunctioning ventricle. That might also be an explanation as to why those patients whose PAP does not change postoperatively do so poorly. I might suggest that perhaps those are the ones with the severely hypertrophied ventricles in whom the major issue is really diastolic dysfunction, which does not clear very quickly.

Dr Melby. Thank you. I appreciate those comments. From my slides, I can show you a graph indicating that we indeed looked at patients with increased PVR, trying to answer the exact question you are asking. Those with an elevated PVR we have separated into greater than 3 Wood units or less than 3 Wood units, trying to tease out what is the left ventricular involvement in this. Those with the higher PVR also did worse, similar to the response of the group with just high $\mathrm{PH}$.

Dr Kevin D. Accola (Orlando, Fla). Dr Melby, to elaborate on Drs Gammie and Griepp's comments, can you apply this clinically now? How have you looked at your patients, particularly those with severe PH? Have you designed a strategy clinically to preoperatively evaluate these or use provocative testing to see which patients truly have reactive $\mathrm{PH}$ relative to their left ventricular dysfunction or truly fixed PH, which I think is another subset and particularly a higher risk category?

Dr Melby. That is an excellent question. We have indeed begun to implement some of these findings in our preoperative workup and we have had provocative testing. However, there is very little published on this, and it is mostly just done by the feelings of the individual surgeon and by our preoperative planning team. We happen to have a nice preoperative planning group devised of anesthesiologists who are very interested in PH. We have looked at this in some patients, and it only takes a few cases of severe PH to go bad for you to realize there is something different with these patients. Thus we are trying to tease those patients out and find out which ones might be higher risk. I do not have any great answers yet, but it is certainly something that needs to be looked at.

Dr Irene Cybulsky (Hamilton, Ontario, Canada). Have you looked at the etiology of the $\mathrm{PH}$, whether it was cardiac or respiratory? Also have you looked at associated tricuspid regurgitation with the degree of PH?

Dr Melby. That is a very good question, and you bring up a good point in that the etiology of $\mathrm{PH}$ can be multifactorial. Unfortunately with the database that we have, there is just no way to find all the answers to the questions you ask. Once again, there is a paucity of literature on this, and this is a great opportunity to find out which factors are going to tease out to be the most significant ones. 